\title{
EMERGENCY SURVEY OF REMOTE AND ENDANGERED ARCHAEOLOGICAL SITES.
}

\author{
F. Fassi ${ }^{\text {a, } *, \text { C. Rossi }}{ }^{\text {b }}$ A. Mandelli ${ }^{\text {a }}$ \\ a Politecnico di Milano, ABC Department, 20133 Milano, Italy - (francesco.fassi, alessandro.mandelli)@polimi.it \\ ${ }^{\mathrm{b}}$ Centro MUSA, University of Napoli "Federico II", 80055, Portici (NA), Italy - progettooasis@ centromusa.it
}

Commission V, WG V/4

KEY WORDS: Close range photogrammetry, 3D reconstruction, emergency survey, archaeology

\section{ABSTRACT:}

The paper describes the survey activities of the late Roman archaeological site of Umm al-Dabadib (Egypt). The interesting casestudy can be taken as an example in case of emergency surveys, as this method allows the complete 3D acquisition of a vast and complex area in a very short time and with the aid of simple instruments.

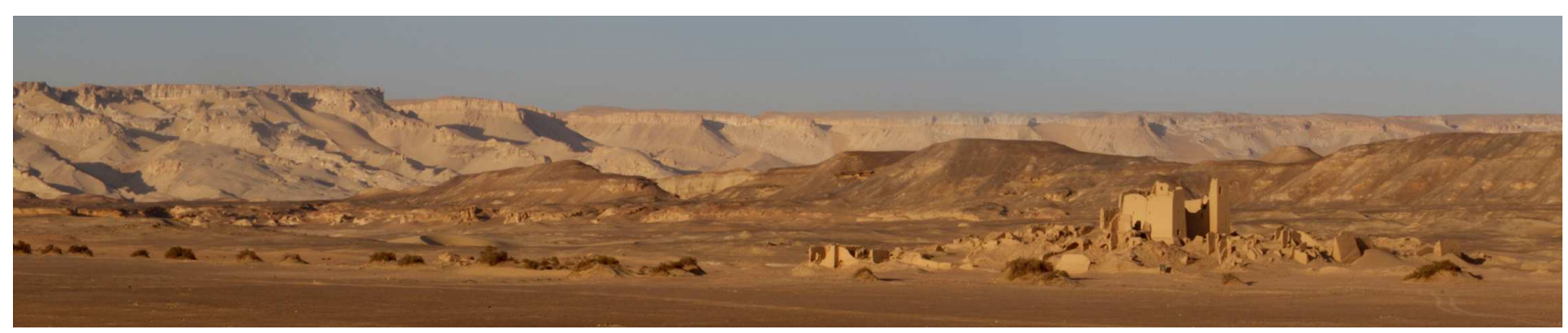

Figure 1. Panorama of Umm el Dabadib (Photo by Fassi F.).

\section{INTRODUCTION}

\subsection{The site.}

Umm al-Dabadib lies at the outskirts of the Kharga Oasis, one of the five large oases of Egypt's Western Desert. It is a vast and well-preserved Roman installation consisting of an inhabited area served by an extensive agricultural system, active in the third and fourth centuries AD. The site was abandoned at the beginning of the fifth century, and apart from a short-lived occupation dating to the early twentieth century (Beadnell 1909), it survived until today relatively intact and virtually unknown. Re-discovered in 1998 by one of the co-authors (Rossi 2000), it is now the object of a multi-disciplinary project aiming at studying in parallel both the settlement and its relating agricultural system, jointly carried out by the Politecnico di Milano and the MUSA Centre of the University of Napoli Federico II.

The site consists of three settlements (the Fortified Settlement, the Northern Settlement and the Eastern Settlement), a Fort, a temple, a church, nine cemeteries, a scatter of minor buildings and a vast agricultural installation including seven underground aqueducts and three cultivated areas. It covers a total area of over 10 square $\mathrm{km}$ and its remains are extremely well preserved. The historical importance of this site is still awaiting a proper evaluation: it is clearly the result of a specific, huge effort to colonise a harsh environment along what was at that time the southern border of the Roman Empire. Its isolation (it lies at a distance of over $40 \mathrm{~km}$ from the oasis' main town) and its adverse climatic conditions (strong winds in winter and spring and stifling heat in the summer), combined with the current lack of available water, had a double effect: on the one hand, they allowed the site to survive in excellent conditions to sixteen centuries of abandonment; on the other hand, they make working there a challenging enterprise, both from a logistic and a financial point of view. Fieldworks must be compact and intense, and not all technology can make it all the way to a place that still lies at the edge of the inhabited world.

\subsection{Previous studies and surveys}

Until 1998, no survey at all existed of the local antiquities. The first cursory survey was conducted basically by hand and on foot and produced a first general sketch of the existing antiquities (Rossi 2000). The relative position of the main features was marked by GPS and the rest inserted by hand; the main buildings were sketched on the basis of a few basic measurements. This first recognition allowed a rough estimate of the existing remains and represented the basis for the birth of the North Kharga Oasis Survey (NKOS), an archaeological project that run from 2001 to 2007.

Co-directed by Dr. C. Rossi (at that time Cambridge University) and Dr. S. Ikram (American University in Cairo), NKOS produced the first scientific explorations and surveys not only of Umm al-Dabadib, but also of the other sites belonging to the chain of Late Roman military-looking installations that punctuate the Kharga Oasis. The 2003 season, funded by National Geographic, was entirely dedicated to Umm al-

\footnotetext{
* Corresponding author. This is useful to know for communication with the appropriate person in cases with more than one author.
} 
Dabadib: NKOS carried out the first scientific survey of the central core of the site, an area of $1 \times 3 \mathrm{~km}$, carried out by means of a theodolite, whereas the farthest features and the long lines of the underground aqueducts were recorded by GPS (Rossi and Ikram 2006). NKOS also experimented aerial photography with the aid of a kite, which yielded significant results in terms of documentation of the nature and extent of this and other sites nearby (Ikram and Rossi 2002).

Looking back at the previous lack of information, these surveys represented a fundamental step towards a better understanding of this still elusive chain of late Roman installations. Looking forward in the direction of a more detailed investigation, they represented a starting point, in need of further refinement: they offer relatively precise information on the location of the various archaeological features, but do not contain the detailed survey of the settlements' subunits (domestic units or groups of houses). For instance, the position of the Fortified Settlement as a whole was fixed thanks to a network of points, but it was impossible to record by theodolite the position of every single wall of every single house. Such an operation would have required weeks of work and would have resulted in a very expensive and tiring expedition. As the site is unlikely to ever change its condition of isolated and remote place, and thus the problems that affect each expedition are likely to remain the same, a different technique had to be adopted to perform a more detailed survey of the local antiquities.

\subsection{The current project}

Umm al-Dabadib is now the focus of a specific project named OASIS (Old Agricultural Sites and Irrigation Systems), born as a spin-off of NKOS. The scope of OASIS is to study in parallel two sets of contemporary remains: the Fortified Settlement and the agricultural system. Planned, designed and built to work together (one could not exist without the other), they represent a unique chance to investigate the foundation of a self-sufficient installation in a harsh and semi-desert area. Moreover, the study of this site is also likely to yield significant information on the Late Roman policy and strategy of control and defence of Egypt's desert frontiers (Rossi 2013).

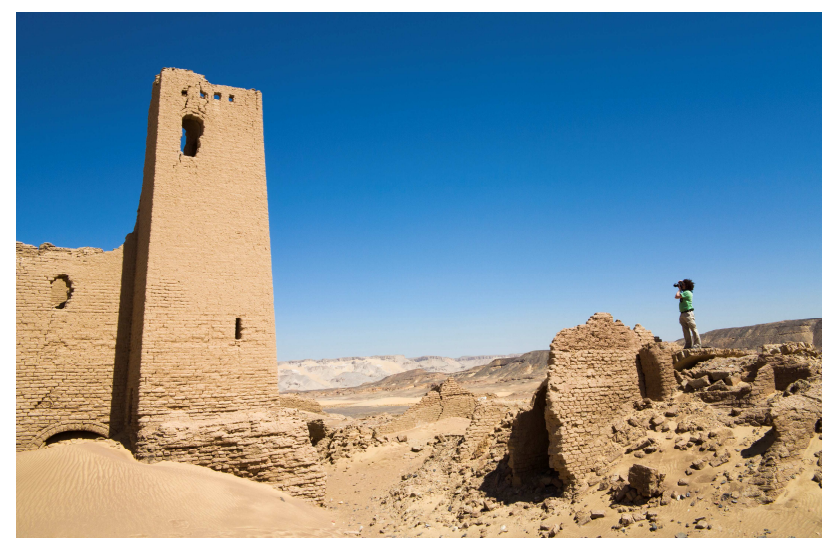

Figure 2. The photogrammteric survey of the castle tower.

The presented paper will describe the survey activities conducted during the 2014 archaeological mission, generously funded by National Geographic and Waitt Institute, with the support of MUSA and Politecnico di Milano. A complete photogrammetric terrestrial survey was performed in order to capture the 3D complexity of the place. The best strategy would have been to use a UAV, eventually integrated with terrestrial acquisitions, which would have allowed a fast acquisition from the air thus speeding up the elaboration phase. However, bureaucratic difficulties made this solution unfeasible: the UAV and others instruments were not allowed to the field and so the survey team was left to face an emergency survey, to be conducted on foot on the ground level. The only instruments at our disposal were a compact camera, a reflex camera, a total station and two photographic tripods.

\section{THE SURVEY}

\subsection{Some methodological general considerations}

Automation: the key aspect for complex, emergency cases. For the elaboration, we used Agisoft Photoscan. This wellknown software (probably one of the best on the market) allows completely autonomous photogrammetric process from the orientation to the construction of a high resolution textured mesh model. It is only thanks to the automation provided by this type of software, that it is possible to tackle a survey like the one presented in this case study.

The past. The use of manual or semi-manual methods have until recently prevented or severely limited the use of an imagebased approach to three-dimensional survey applied on large and complex objects. The main reason was the need to acquire a very high number of images and to collect manually a huge number of tie points.

A further problem was the camera calibration. Until recently, it was essential to use semi-metric cameras or pre-calibrate digital consumer camera off-site. This aspect has always limited "a free photographic acquisition" forcing the operator to shot at predetermined distances and using pre-calibrated fix focal values. Some methods of on-site pre-calibration allowed to set and pre-calibrate the camera on the field.

Until recently the high number of images, the manual collection of tie points and the need of camera pre-calibration have been the main reasons why the photogrammetric techniques were extremely time-consuming and challenging, normally reserved to industry experts. Some interesting case of the past, as the survey of Pompei Forum (Guidi G., et al., 2008) and the main Spire of Milan's Cathedral (Fassi et al., 2011), are clear examples that photogrammetric surveys of large heritages were possible, but required a long time, a large group of operators and sensor integration..

Substantially close-range image-based surveys of large and complex areas were virtually impossible, especially in emergency cases where short elaboration time and low costs are inalienable necessities. That has favoured the use of TLS techniques, that are far more expensive but definitely allow a simpler and fast three-dimensional real-time survey of environments, architectures and large dimension objects.

The automatic image based methods. The marriage between photogrammetry and image analysis techniques typical of computer vision have revolutionized in recent years and are still revolutionizing the way to measure objects, especially in the field of Cultural Heritage. (Barazzetti L., et al., 2009) The software born from this match basically work like photogrammetric software following the classical pipeline but using automatic methods of point recognition. This allows a complete automatism in the image orientation phase and the possibility to extract dense $3 \mathrm{D}$ point cloud in relative short time. In the extreme case, particularly interesting in case of emergency, the process can be entirely and automatically performed without any intervention by the operator from the beginning to the end. We no longer speak of automation of the process but of autonomous process.

This involves the possibility to orientate in a short time and without "loss of time" a substantial number of images thus 
allowing the acquisition of images for large environments or complex objects.

The identification of a high number of points allows a "very high observation redundancy" that normally leads to stable solutions and a simultaneous camera self-calibration (Gruen, 2001). This allows to: i) avoid pre -calibration steps, ii) to manage different cameras in the same process or iii) change camera settings during the acquisition. It is possible for example to use auto focus and different zoom levels.

Thus the acquisition camera is released by the past photogrammetric constrains retrieving the flexibility and "ease of acquisition" typical of photography. Aware of the possible consequences in terms of achievable measurement accuracy, these simplifications allow freedom of movement around the object, multi-scale acquisition, and make possible the acquisition of objects in difficult position.

Is equally important to consider the economic aspect. Surveying with a photo camera is extremely low cost.

These features make image based method ideal for Cultural Heritage and for complex areas, especially in case of an emergency.

The case of study here presented is the occasion to describe a good practice to survey also with makeshift equipment, showing as some rules of the past and few precautions can provide high quality results in terms of accuracy and completeness of the results.

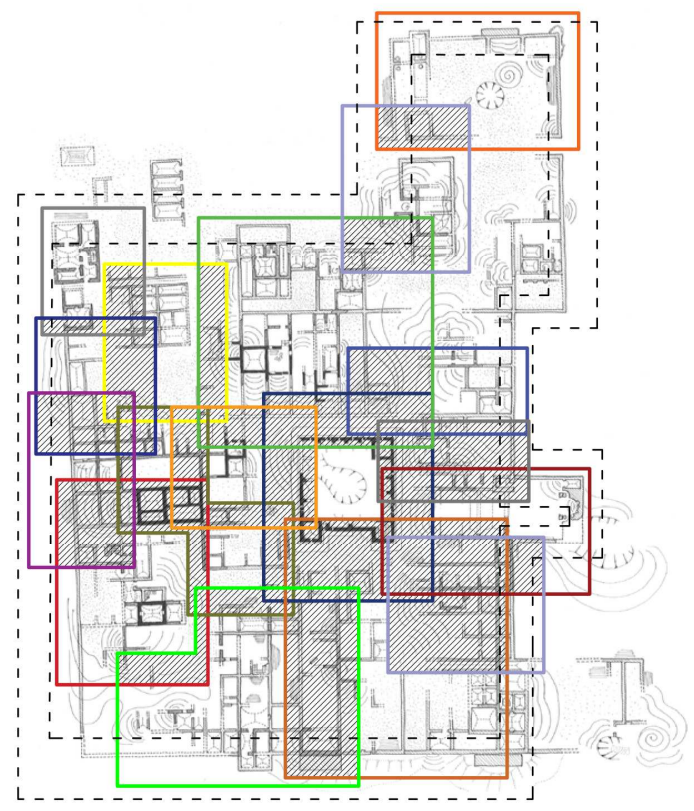

Figure 3: The subdivision of the area in the 18 sub/areas. The hatched parts are the main overlap among the different image blocks.

\subsection{The area to be surveyed and its issues}

The 2014 season of OASIS focussed on the Fortified Settlement. This is a compact, L-shaped, built-up area, covering an area of about 100 square metres. It is surrounded by a linear wall and crossed by long, parallel walls among which the various domestic units were inserted. No open-air streets have been found (apart from a passage all around the Fort): the settlement was served by long vaulted passages, some running one on top of the other. This means that the settlement was basically solid: this arrangement allowed the best protection from the strong sun and sand-laden winds that batter the area. Over the centuries, the compact design of the Fortified Settlement generated a solid an undulating mass of ruins: the upper portions of the houses still stand, but parts collapsed and created tall mounds and deep depressions. It is possible to walk among the mounds corresponding to groups of buildings and even to carefully climb on them, but this situation adds to, rather than reduces, the complexity of the object to be surveyed. The uneven ground, the strong and changing light, and the time constrain required the team to subdivide the work into small portions and to engineer ad hoc solutions to solve specific problems, as we shall see below.

\subsection{The survey phase}

2.3.1 The survey design. Due to extension of the archaeological site, the natural choice was to divide all the area in sub/areas. Each area corresponds to a specific building. The subdivision is designed ad hoc in order to complete the survey with a sufficient overlap with neighbour areas. Further subdivision in micro-areas is done to complete the "interiors" of the buildings or specific interesting object as arcs, ceilings and pillars. An external, circular take of images around the perimeter was also done in order to materialize a closed external constrain. This created photogrammetric block is used to check the global alignment. (View table 1)

Some practical tricks in order to avoid lack of data or difficulties during the bundle adjustment are:

- to use ups and downs of the terrain to acquire object from progressive raised positions. In this case the natural mounds of rubble were very useful to acquire the upper parts of the buildings.

- to design the acquisition during the hours of noon when the sun creates fewer shadows on the ground and on the structures.

- $\quad$ to speed up the acquisition of the single area in order to avoid dramatic changes of light;

- to take care to framing of every shots, avoiding, if possible, large chunks of sand and sky on the images that could cause problems during image orientation phase.

2.3.2 Topographic survey. For a complex structure, it is be very important to have a good net of GCP useful to georeference all data together, to scale correctly the single models and to have sufficient check points to estimate the accuracy of the reconstruction. (Fassi et al., 2007) In archaeological and architectonical case studies, this continues to be a valid paradigm even if today many procedures are becoming more and more automatic, quite autonomous and user-friendly, and seems to promise perfection without any intervention.

In many emergency cases, one does not necessarily have a topographic instrumentation at one's disposal, and maybe the accuracy and precision of the survey are secondary to the need to take home a result as complete as possible and as quickly as possible. For this reason, one can follow simple tricks which allow to obtain results close to the true without following, by necessity and compulsion, ideals procedures.

We fortunately had a total station, but without additional necessary instrumentation (no tripods, topographic bases, tricuspids and prisms) in order to build a right triangulation network. A good photographic tripods was converted on site for topographic instrumentation and the other one was transformed in "target reference tripods" to materialize all the networks 
points. In order to assure the verticality we use a bubble level tied to the tripod legs with normal tape. A distinctive cross mark on the tripod was used as target point.

The initial idea was to materialize a close network around the central castle but the presence of huge amount of sand and the understandable difficulties allowed us to materialize a network only in the southwest portion of the field thus allowing the detection of at least three sides of the village and of two sides of the main castle. The network was created as a closed triangle using two point on the same ground level and one more point in a higher position. A global 3D accuracy of about $4 \mathrm{~mm}$ was obtained. The areas covered by the network are used as reference block to georeference and scale all the other blocks together.

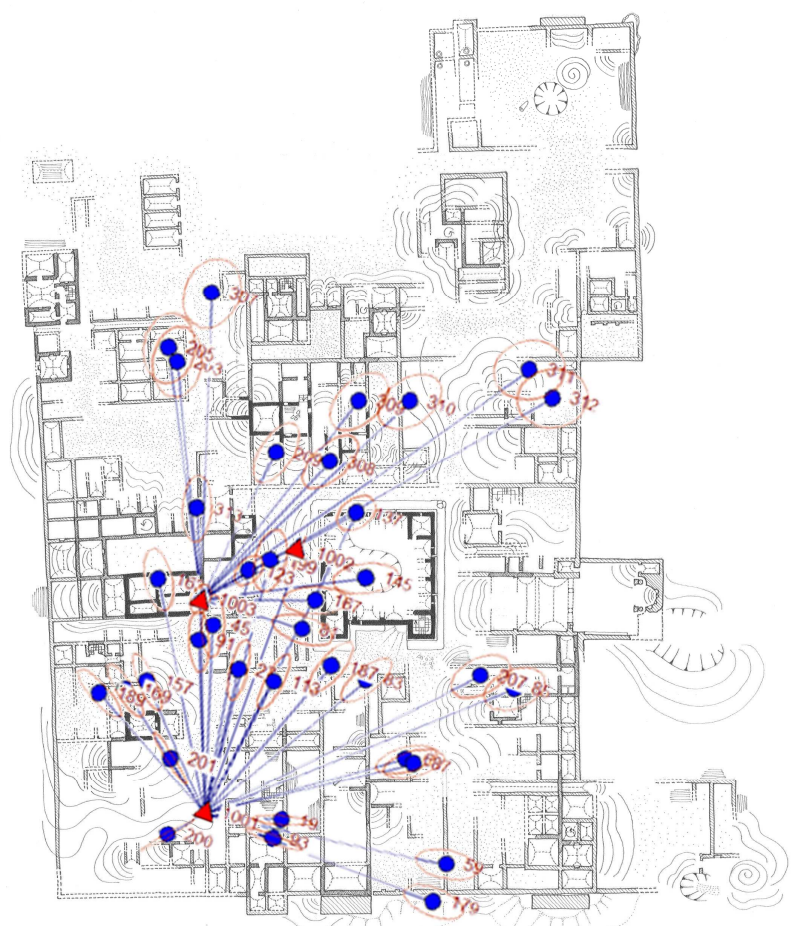

Figure 4. The topographic network. The red triangle are the tree base station.

2.3.3 The photogrammetric acquisition. The best capture geometry to adopt in this case is a closed circular acquisition around every "building". This helps, like a closed traverse, to reduce automatically image orientation errors and false inner orientation parameters calculation without the use of GCP or other geometric external constrains. It is how to create a closed traverse but only made of images.

It is very important, if possible, to use targets because necessary in the photogrammetric elaboration even if you do not have at disposal a topographic instrumentation. You can build or draw and materialize them very quickly and in many ways even using makeshift materials. Where impossible, it is strongly recommended the use of physic architectonical points picked manually on the images as reference points. This happened in particular in the presence of high inaccessible structures

Targets should be well-positioned on the structures. It means that: i) they should be distributed quite uniformly on the structures, ii) they should be seen by a sufficient amount of images iii) in that areas where the geometry is particularly complex and the automatic processes can fail. Targets help a lot in particularly complex areas to tie up discontinued structures and badly illuminated areas. If distributed uniformly in the areas, they act as external constrains to the process of the image orientation and allow a better calculation of lens distortion parameters in the auto-calibration process.

In total, we shot 5100 images using a Canon 5D MarkIII with fix $35 \mathrm{~mm} \mathrm{~F} 2$ lens and one Canon G1X. The reflex camera was mainly used for the main buildings and for the largest areas, due to the high resolution $(22,3 \mathrm{Mp})$, the high quality lenses, and the major configuration possibilities. The compact one was used for the smaller building, for small details and when it was necessary to climb some structures or enter in some narrow places.

Every image blocks was pre-oriented in low resolution during the night to verify on site the quality of the image orientation and the completeness of the areas covered by the survey.

Even if the elaboration software provides a result to achieve a high-quality results in terms of accuracy, some photographic practical rules must be followed. (Nocerino et al, 2014) These rules were valid in the past and are even more essential today, because the process is nearly completely automatic and the operator cannot intervene in the process of identification of points. For these reason, even more than in the past, the image quality should be superb.

\begin{tabular}{|c|c|c|c|c|c|}
\hline & $\begin{array}{c}\mathbf{N}^{\circ} \text { of } \\
\text { images }\end{array}$ & $\begin{array}{c}\text { Total } \\
\text { Error } \\
\text { (Pix) }\end{array}$ & $\begin{array}{c}\text { Total } \\
\text { Error } \\
\text { (m) }\end{array}$ & $\begin{array}{c}\mathbf{N}^{\circ} \text { of } \\
\text { GCP } \\
\text { (Target) }\end{array}$ & $\begin{array}{c}\mathbf{N}^{\circ} \text { of } \\
\text { aGCP } \\
\text { (architect } \\
\text { onical) }\end{array}$ \\
\hline Castle & 509 & 0.343 & 0.003 & 10 & \\
\hline $\begin{array}{l}\text { Little } \\
\text { House }\end{array}$ & 197 & 0.336 & 0.001 & 3 & \\
\hline $\begin{array}{l}\text { The } \\
\text { Church }\end{array}$ & 121 & 0.256 & 1 & 2 & 3 \\
\hline $\begin{array}{c}\text { Mountain } \\
\text { vessels }\end{array}$ & 257 & 0.290 & 1 & 2 & 4 \\
\hline Building 1 & 182 & 0.739 & 0.008 & 7 & \\
\hline Building 2 & 260 & 0.777 & 0.008 & 11 & \\
\hline Building 3 & 412 & 0.252 & 0.004 & 7 & \\
\hline Building 4 & 444 & 0.601 & 0.006 & 17 & \\
\hline Building 5 & 265 & 0.353 & 0.002 & 4 & 1 \\
\hline Building 6 & 176 & 0.308 & 0.005 & 4 & 1 \\
\hline Building 7 & 123 & 0.229 & 0.001 & 3 & \\
\hline Building 8 & 158 & 0.611 & 0.010 & 3 & \\
\hline $\begin{array}{c}\text { Big } \\
\text { Building } \\
\end{array}$ & 1051 & 0.093 & 0.005 & 4 & 4 \\
\hline North side & 126 & 0.188 & 1 & & 6 \\
\hline North ruins & 226 & 1 & I & 1 & \\
\hline West ruins & 93 & 0.184 & 1 & 4 & 4 \\
\hline $\begin{array}{c}\text { Church } \\
\text { ruins }\end{array}$ & 157 & 0.483 & I & 2 & 4 \\
\hline Perimeter & 341 & 1,214 & 0.017 & I & $\begin{array}{c}10 \\
\text { (common } \\
\text { with } \\
\text { other } \\
\text { blocks) }\end{array}$ \\
\hline Total & 5098 & & & & \\
\hline
\end{tabular}

Table 1. Summary table of the diverse image block. In bold characters the blocks covered by total station survey used as reference for the whole area. On the right columns the number of target GCP and manually added architectonical ones (aGCP).

During the acquisition at Umm El Dabadib all images were taken in raw format. This implies to post elaborate the images but allow working on shadows areas, lightning some details and in general increasing contrast and clarity of the images. (Guidi et al., 2014). The best choice would have been to work with fix focal lens, but due to the extension of the area, the extremely tight timetable and the sudden changes of light we decided to speed up the acquisition. In order to avoid dramatic changes of 
focal and achieve a better precision, we tried to maintain the same average distance to the object using always hyper-focal. This is a right way to maintain greater depth of field and limit focal changes

Averagely the capture distance was around 10-15 meters for building acquisition and 5-6 meters for the details. Only for the central castle was used a largest distance, circa $15-20 \mathrm{~m}$. The choice was taken for two reason: i) to facilitate the acquisition in a single block of the high castle walls and ii) to frame in the foreground all the surrounding structures useful for the automatic recording of the blocks. The sensor resolution and the planned capture geometry assured a medium GSD (Ground Sample Distance) of $1 \mathrm{~mm}$ for front objects (object of the survey) and a max of $5 \mathrm{~mm}$ for back objects (useful for registration with others block). The images were acquired with a mean overlap between two consecutive normal views of about $80 \%$ to guarantee the automated identification of homologous features and assure a minimum number of intersecting rays for improving reliability. The mean baseline between adjacent images was about $1.5 \mathrm{~m}$ with a max of $5 \mathrm{~m}$ for more distant object.

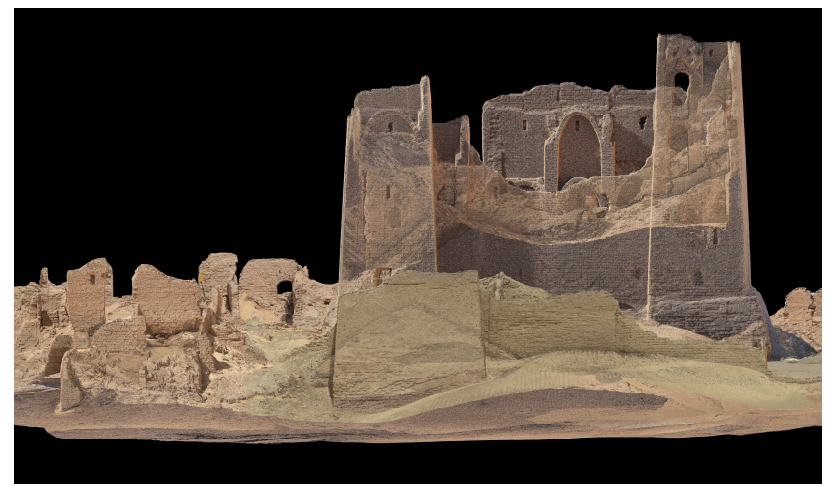

Figure 5. Orthoimage of the external façades of the castle. In transparency the internal areas. It is clearly possible to study the level of internals remains and buildings techniques.

The average base/distance ratio was of 0.1 . When in the presence of long walls, as for external wall block, convergent images were also acquired assuring a $\mathrm{B} / \mathrm{D}$ ratio of 0.5 . In the presence of sharp edges, the image base was reduced. For more simple building was used a circular convergent capture geometry centred in the hypothetical centre of gravity of the object and moving the camera of circa $10^{\circ}$.

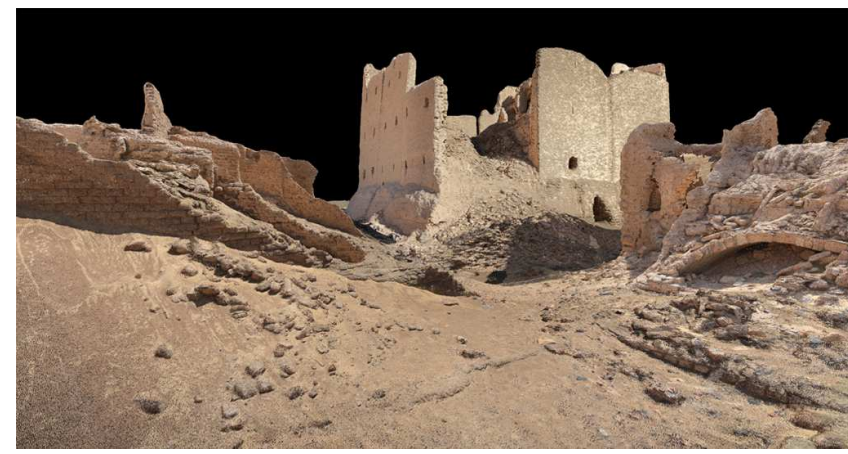

Figure 6. An interesting "Point Cloud view" of the central castle from the actual entrance.

\subsection{The automatic elaboration process.}

The orientation. As already said we used Agisoft Photoscan for all the process. All the elaboration were conducted using full resolution images for orientation. Each image block was processed separately and optimized using GCP recognized manually in a second phase. This was conducted without assigning the coordinate acquired by total station. These data were added in a third phase to georeference and scale the model. In this way accidental error coming from topography did not affect the orientation. In two cases only, due to a lack of data, some GCPs were added manually before the orientation process in order to compute the incomplete orientation.

In a fourth step all block were aligned together sequentially, starting from the southwest block and gradually adding one by one all the neighbouring blocks. The alignment of the blocks was made using the "point-based" method that uses only image matched points to scale and rigidly align all the block together. The final accuracy was checked step by step using the deviation among common GCPs and, where missing, visually extracting small sections of point cloud to inspect any misalignments.

At the end all, the internal blocks were positioned together with the external view that runs all around the area. This was a sort of final global check of the global alignments. The mean georeferencing errors on the common GCPs was $15 \mathrm{~mm}$ with a max error of $21 \mathrm{~mm}$.

The model. The dense matching was done in high quality, which means an image size reduction by the factor of 4 . Due to the high initial image resolution the dense point cloud have a final resolution of circa $5 \mathrm{~mm}$ for a total of circa 650 million of points. It is a sort of very high density LIDAR point cloud from which it is possible to extract 3D models, orthophotos, videos and interesting views and representations.

\section{RESULTS AND FUTURE APPLICATIONS}

The results are impressive. The feasibility of the survey of each single building was quite clear from previous work (Fassi at al., 2013) and literature (Gonizzi, 2013; Forte 2013).. The general accuracy achieved by the whole process, instead, was not that obvious. Following the described rules of good practice, the general final precision is sub-centimetre and uniform in all areas.

Moreover, the survey is complete and the point model has very high resolution, significantly higher than the classical resolution suitable for architectural representation typical in these cases.

In the specific case of Umm al-Dabadib, a photogrammetric 3D survey represented the quickest and most efficient way to record the huge mass of information yielded by the Fortified Settlement, thus allowing the project to use in a more efficient way the significant financial resources that would have been absorbed by a classic theodolite survey. The same method could be adopted to survey endangered archaeological sites, when a quick and precise documentation of the visible evidence represents the only work that archaeologists might ever be able to perform.

Among future applications, there is the survey of indoor environments. The use of fisheye lens and nets of panorama images are being studied and tested to be used on the next survey mission in Umm el Dabadib (25 January -5 February 2015) . Fisheye survey will results very useful to speed up and simplify the acquisition of particularly narrow areas; panoramas could be very useful for very large environment.

Needless to say that the use of a UAV would have facilitated and speeded up the survey, even if a survey from the ground would still be necessary to integrate the aerial data. The 
impossibility to survey from a highest point of observation is the only negative aspect of this experience. In fact, it was impossible to survey the top of the farthest buildings from the castle.

The collected data may represent the basis for a number of possible operations. First, the data themselves represent a faithful representation of the current state of the archaeological remains in a certain moment; this can be later used to monitor the natural decay of the ruins or, in the worst case, of the damages inflicted by vandals. A comparison between these data with old surveyed data could be also useful to understand how the place has changed in the last 10 years: by comparing the old village map on figure 3 and figure 4 with the orthoimage in the figure 7 , it is immediately clear that many areas have disappeared in just a few years.

The survey can be used to study the layout of the settlements, the alignment of the various buildings, as well as the design of the various units. Finally, these data can also be used to prepare a digital reconstruction of the original appearance of the site, to be used both for academic purposes and for popular publications.

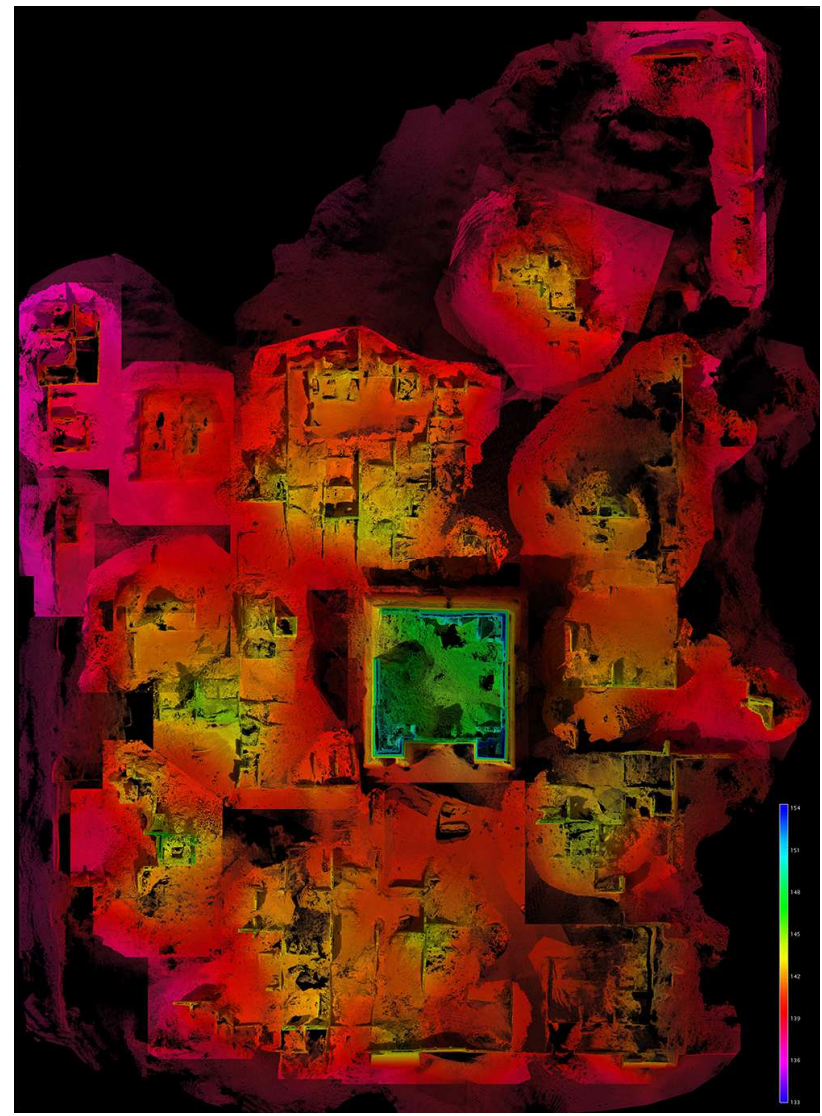

Figure 7. Orthophoto of the complex. The images is visualized as a depth map to better understand the different elevation of the buildings.

\section{CONCLUSIONS}

The survey technique described in this article proved to be efficient and successful. The possibility to use simple instruments and to quickly obtain the raw data make it the ideal survey technique to be used in the case of logistically challenging sites as well as endangered archaeological sites. This technique allows an unparalleled combination of precision and speed, as well as the collection of a large number of raw data that can later be processed and reused for different scopes. In 2014 we performed the 3D survey of the Fortified Settlement, and we are planning to extend the survey to the Eastern and Northern Settlements as well. The same method, however, could be extended to other archaeological features of the site of completely different nature: the cultivations. The ancient fields are barely visible from the ground, and their layouts can only be spotted for a few minutes at dawn and sunset when the sun is low; surveying them from the ground is out of the question, and would anyway yield a poor result. An aerial survey performed with a drone, instead, is likely to offer precise and detailed results, that would be otherwise impossible to obtain. We hope to be able to experiment on this front and to report our results on a later occasion.

\section{ACKNOWLEDGEMENTS}

We wish to express our gratitude to the National Geographic Society and the Waitt Institute for their generous grant in support of the 2014 expedition. We also wish to thank Dr. C. Achille (Politecnico di Milano) and Prof. S. Mazzoleni (Centro MUSA) for their support and advice. Thanks to the Supreme Council for the Antiquities of Egypt for allowing our work; to the Chief Inspector of the Kharga Oasis Mr Ahmed I. Bahgat and to our field inspector Mr Ahmed Moussa for their support on the field; to Mr Magdy Aly for his collaboration as Project's Representative in Egypt; to Mr Ahmed Moussa and Ms Marwa Fawzy (Pan Arab Tours) for their logistic and personal support; and last but not least, to the expedition's supporting team: Hamdy, Walid and Muhammad and Shukri.

\section{REFERENCES}

Beadnell, H. J. Ll., 1909. An Egyptian Oasis, London 1909.

Barazzetti L., Remondino F., Scaioni M., 2009. Combined use of photogrammetric and computer vision techniques for fully automated and accurate 3D modeling of terrestrial objects. In Proc. SPIE 7447, Videometrics, Range Imaging, and Applications X, 74470M (September 03, 2009); doi:10.1117/12.825638; http://dx.doi.org/10.1117/12.825638

Fassi F., 2007. 3D modeling of complex architecture integrating different techniques - a critical overview. In: Int. Archives of Photogrammetry, Remote Sensing and Spatial Information Sciences. Zurich, Switzerland, vol. XXXVI-5/W47

Fassi, F., Achille, C., Gaudio, F., and Fregonese, L., 2011. Integrated strategies for the modeling very large and complex architectures, Int. Arch. Photogramm. Remote Sens. Spatial Inf. Sci., XXXVIII-5/W16, 105-112, doi:10.5194/isprsarchivesXXXVIII-5-W16-105-2011.

Fassi F., Fregonese L. Ackermann S., De Troia V., 2013. Comparison between laser scanning and automated 3D modelling techniques to reconstruct complex and extensive cultural heritage areas. ISPRS Workshop 3D-ARCH: 3D virtual reconstruction and visualization of complex architectures, Trento, 2526 February 2013

Forte, M, Dell'Unto, N., Haddow, S., Lercari, N., 2013. 3D Documentation at Çatalhöyük: New Perspectives for Digital Archaeology. Proceedings of Digital Heritage 2013, Marseille, 2013, IEEE. October, 2013. 
Gonizzi Barsanti, S., Remondino, F., and Visintini, D., 2013. 3D surveying and modeling of archaeological sites - some critical issues -, ISPRS Ann. Photogramm. Remote Sens. Spatial Inf. Sci., II-5/W1, 145-150, doi:10.5194/isprsannals-II5-W1-145-2013.

Gruen, A., Beyer, H. A., 2001: System calibration through selfcalibration. In Calibration and Orientation of Cameras in Computer Vision, Gruen and Huang (Eds), pp. 163-193.

Guidi, G., Remondino, F., Russo, M., Menna, F., Rizzi, A., Ercoli, S., 2009. A Multi-Resolution methodology for the 3D modeling of large and complex archaeological areas. International Journal of Architectural Computing, Vol. 7(1), pp. $39-55$

Guidi, G., Gonizzi, S., and Micoli, L., 2014. Image preprocessing for optimizing automated photogrammetry performances, ISPRS Ann. Photogramm. Remote Sens. Spatial Inf. Sci., II-5, 145-152, doi:10.5194/isprsannals-II-5-145-2014.

Guidi, G., Remondino, F., Russo, M., Rizzi, A., Voltolini, F., Menna, F., Fassi, F., Ercoli, S., Masci, M.E., Benedetti, B., 2008. A multi-resolution methodology for archeological survey: the Pompeii Forum. Proc. of 14th Int. Conference on Virtual Systems and MultiMedia (VSMM 2008), pp. 51-59, Limassol, Cyprus

Haukaas, Colleen, 2014. New Opportunities in Digital Archaeology: The Use of Low-Cost Photogrammetry for 3D Documentation of Archaeological Objects from Banks Island, NWT. University of Western Ontario - Electronic Thesis and Dissertation Repository. Paper 2117.
Nocerino, E., Menna, F., and Remondino, F., 2014. Accuracy of typical photogrammetric networks in cultural heritage 3D modeling projects. Int. Arch. Photogramm. Remote Sens. Spatial Inf. Sci., XL-5, 465-472, doi:10.5194/isprsarchives-XL5-465-2014, 2014.

Remondino F., Del Pizzo S., P. Kersten T., Troisi S., 2012. Low-Cost and Open-Source Solutions for Automated Image Orientation - A Critical Overview. In: Lecture Progress in Cultural Heritage Preservation. Notes in Computer Science Volume 7616, pp 40-54

Rossi, C., 2000. Umm el-Dabadib, Roman Settlement in the Kharga Oasis: Description of the Visible Remains. With a Note on 'Ayn Amur. MDAIK 56, pp. 235-52.

Rossi C., 2013. Controlling the borders of the empire: the distribution of Late-Roman 'forts' in the Kharga oasis, in Bagnall R., Davoli P, and Hope C. (eds.) The Oasis Papers 6, Proceedings of the Sixth Conference of the Dakhla Oasis Project, , Dakhla Oasis Project Monograph 15, Oxford: Oxbow, 2013: 331-6.

Rossi, C. and Ikram, S., 2006. North Kharga Oasis Survey 2003. Preliminary Report: Umm el-Dabadib. MDAIK 62, pp. 279-306.

Ikram S. and Rossi, C., 2002. Surveying the North Kharga Oasis. KMT 13(4), pp. 72-9.

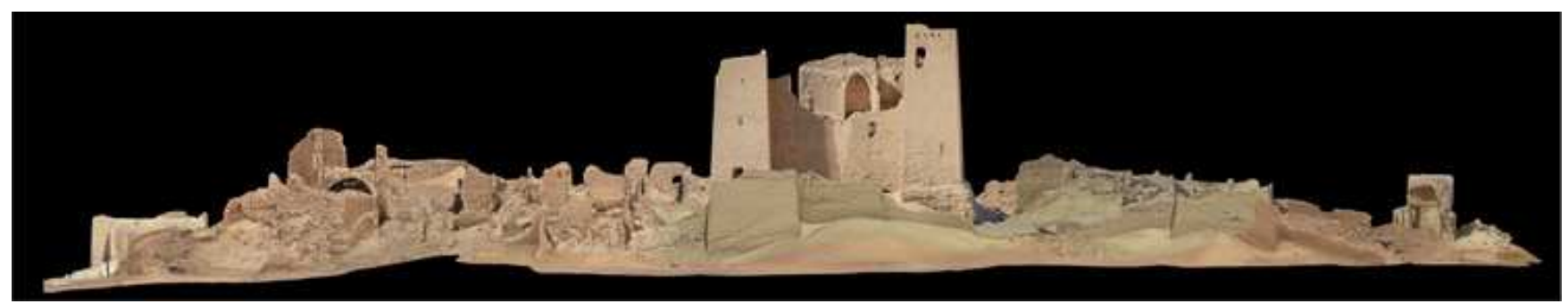

Figure 8 . The south view of the settlement extracted from the high-resolution point cloud.

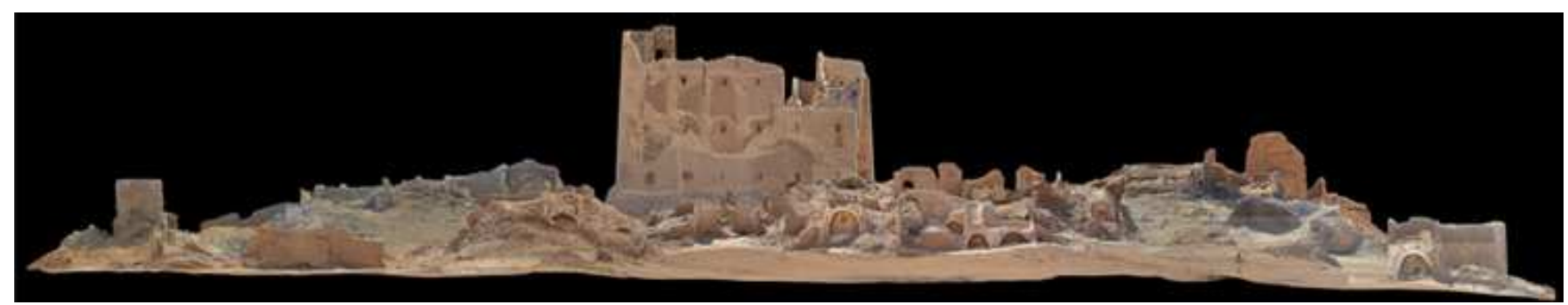

Figure 9. Northern Prospect of the Fortified Settlement (slightly transparent).

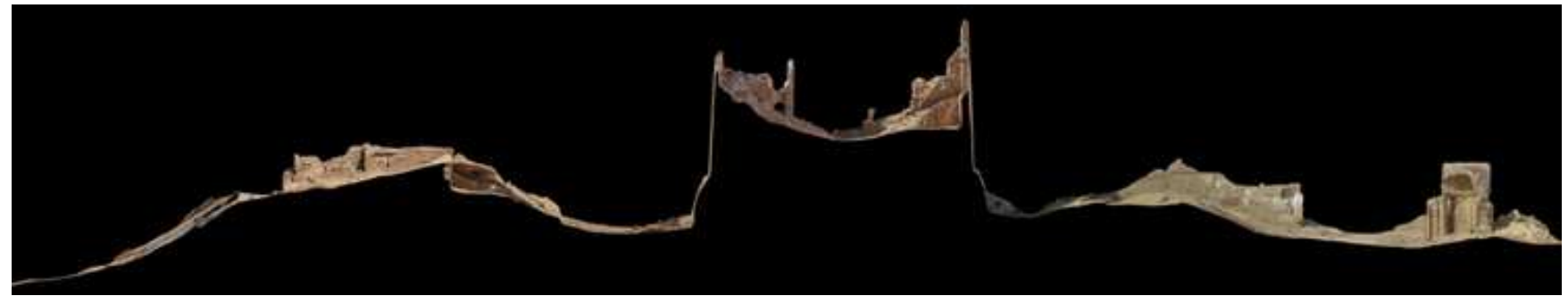

Figure 10. East-West Section of the Fortified Settlement. 